\title{
RECCHIA SESSILIFLORA (SURIANACEAE ARN.), UNA ESPECIE NUEVA DE LA CUENCA DEL BALSAS EN EL ESTADO DE GUERRERO, MÉXICO
}

\author{
Andrés GonZÁlez-Murillo ${ }^{1}$, Ramiro CruZ-Durán ${ }^{2,3}$ y Jaime Jiménez-RamíreZ ${ }^{2}$ \\ ${ }^{1}$ Universidad Nacional Autónoma de México, Facultad de Ciencias, Departamento \\ de Ecología, Delegación Coyoacán, 04510 México, D.F., México. \\ ${ }^{2}$ Universidad Nacional Autónoma de México, Facultad de Ciencias, Departamento \\ de Biología Comparada, Delegación Coyoacán, 04510 México, D.F., México. \\ ${ }^{3}$ Autor para la correspondencia: ramcrudur@yahoo.com
}

\section{RESUMEN}

Se describe e ilustra a Recchia sessiliflora (Surianaceae Arn.), una especie nueva de la Cuenca del río Balsas en el estado de Guerrero, México. El nuevo taxon es afín a Recchia connaroides (Loes. \& Soler) Standl., pero difiere de ella por tener folíolos más pequeños, que aumentan de tamaño hacia el ápice de la hoja, elípticos a suborbiculares, el raquis con alas evidentes, las inflorescencias en espiga y los pétalos oblanceolados con el ápice irregularmente emarginado. Esta especie se conoce hasta ahora solo de la localidad tipo, creciendo en bosque tropical caducifolio. Se presenta una comparación de las características de las especies afines, un mapa de distribución y una clave dicotómica para el reconocimiento de las especies conocidas del género Recchia Moc. \& Sessé ex DC.

Palabras clave: Cuenca del río Balsas, Guerrero, México, Recchia, Simaroubaceae, Surianaceae.

\section{ABSTRACT}

A new species from the Balsas Depression in the state of Guerrero, Mexico, Recchia sessiliflora (Surianaceae Arn.), is described and illustrated. This new species is similar to Recchia connaroides (Loes. \& Soler) Standl., differing from the latter in having smaller, elliptic to suborbicular leaflets which increase in size towards the apex of the leaf, a rachis which is clearly winged, a spicate inflorescence and flowers with oblanceolate and irregularly 
emarginate petals. This species is currently only known from its type locality in tropical dry forest. A comparative table with distinctive characteristics of similar species, a distribution map, and a dichotomous key to distinguish among the known species for the genus Recchia Moc. \& Sessé ex DC. are also provided.

Key words: Balsas Depression, Guerrero, Mexico, Recchia, Simaroubaceae, Surianaceae.

Durante las exploraciones botánicas efectuadas para conocer la diversidad de la flora arbórea del estado de Guerrero se recolectaron en el bosque tropical caducifolio del municipio de Cocula, algunos ejemplares botánicos con hojas compuestas, con folíolos alternos, el raquis evidentemente alado y dispuesto en zig-zag, flores actinomorfas, cáliz y corola pentámeros, sépalos y pétalos libres, estambres libres y obdiplostémonos (10), gineceo apocárpico, bicarpelar, los carpelos situados sobre ginóforos cortos, cada carpelo con dos óvulos, estilodios unidos cerca de la base de los carpelos y fruto drupáceo; lo que permitió identificar a dichas muestras como pertenecientes al género Recchia Moc. \& Sessé ex DC. (Surianaceae), de acuerdo con el criterio de Schneider (2007).

El género Recchia tradicionalmente se había ubicado en la familia Simaroubaceae, aunque Wendt y Lott (1985) y Thomas (1990) señalaron que debido a las características florales (principalmente por la apocarpía, estilodios basifijos y carpelos biovulados), el género debía colocarse en Surianaceae. No es sino hasta la realización del estudio de la filogenia molecular de Crayn et al. (1995) que se sitúa incuestionablemente dentro Surianaceae, bajo la circunscripción de Cronquist (1981). Asimismo, Crayn et al. (1995) propusieron como grupo hermano al género australiano Cadellia F. Muell. por compartir caracteres morfológicos como el gineceo apocárpico, los carpelos biovulados, la placentación marginal-basal, los estilos ventrobasales y el fruto con pericarpio de tres capas. La familia Surianaceae se incluye en el orden Fabales del clado Eurrósidas (Stevens, 2001 y en adelante; Kubitzki, 2007).

Recchia contaba con tres especies reconocidas y era un género considerado completamente restringido a México (Villaseñor, 2004; Schneider, 2007; Rzedowski y Calderón, 2013), hasta que recientemente una de ellas fue colectada en Centroamérica. La distribución de $R$. mexicana Moc. \& Sessé y $R$. connaroides (Loes. \& Soler) Standl. está restringida al bosque tropical caducifolio de la vertiente del Pacífico, desde Jalisco hasta Oaxaca. En tanto que $R$. simplicifolia Wendt \& Lott se distribuye en el bosque tropical perennifolio, en los estados de Chiapas, Oaxaca, 
Tabasco y Veracruz (región de Uxpanapa) y recientemente se han colectado algunos especímenes en Puntarenas, Costa Rica (Aguilar y Hammel 610; CR, MO y Herrera 4291; CR, MO; Tropicos.org, 2013) (Fig. 2).

Los cinco géneros de la familia Surianaceae forman dos clados, uno constituido por Recchia y Cadellia (endémico a Australia), y otro por el género monoespecífico pantropical Suriana L. y los australianos Guilfoylia F. Muell. y Stylobasium Desf. (Crayn et al., 1995). Los dos géneros presentes en México (Recchia y Suriana) tienen distribuciones disyuntas con respecto a sus grupos hermanos y también dentro del país. A pesar de que las diásporas de Suriana maritima L. se dispersan por medio de corrientes marinas (Nooteboom (1962) citado por Schneider, 2007), solo se conoce del occidente del Océano Atlántico (Gutiérrez, 2011), el este de África, así como en las islas tropicales del Pacífico (incluida Australia), donde crece en las playas y áreas costeras.

De acuerdo con la filogenia molecular de Thompson et al. (2001), la tribu Brongniartieae Hutch (Fabaceae) tiene una distribución similar a la observada en la familia Surianaceae. En este grupo, los géneros Brongniartia Kunth y Harpalyce Sessé et Moc. se distribuyen principalmente en México y parte de Sudamérica; no obstante, los taxones del grupo hermano de Brongniartia se encuentran en Australia (Hovea R. Br., Templetonia R. Br., Lamprolobium Benth., Plagiocarpus Benth.). Estos ejemplos muestran evidencias de que la relación biogeográfica entre la flora de México y Australia, hasta ahora poco documentada, pueda ocurrir en otros grupos de plantas, revelando un patrón biogeográfico bien definido.

La especie que a continuación se describe tiene una reducción de la inflorescencia, pasando de la panícula característica del género (Schneider, 2007) a una espiga.

\section{Recchia sessiliflora González-Murillo \& Cruz Durán, sp. nov.}

$R$. connaroidi (Loes. et Soler) Standl. affinis sed folioliis ellipticis vel suborbicularibus, brevioribus, rhachidi alata, inflorescentiis spicatis, floribus sessilibus, petalis oblanceolatis et emarginatis apice.

Árboles de 6-10 m de alto, caducifolios; tronco tortuoso de corteza rojiza; ramas jóvenes teretes, creciendo en zig-zag, con pubescencia blanca velutina, glabrescentes con la edad. Hojas alternas, compuestas, imparipinnadas, de (5.8-)9.2$12.8(-14.5) \mathrm{cm}$ de largo, folíolos alternos; estípulas de menos de $1 \mathrm{~mm}$ de largo, brevemente lanceoladas, con margen eroso; pecíolo de (0.5-)1.1-1.3 mm de largo, 
particularmente velutino en la superficie abaxial; raquis conspicuamente alado, creciendo en zig-zag a cada lado del raquis; ala del raquis de 3.5-4 mm de ancho, pilosa; folíolos (5-)7(excepcionalmente 9), incrementando en tamaño hacia el ápice de la hoja, de (2.3-)2.7-6.1(-6.8)×(1.6-)2-3.4 cm, elípticos, raramente suborbiculares, base y ápice obtusos, el haz y envés blanco velutinos, particularmente en las venas de segundo, tercero y cuarto grado, el margen entero, ligeramente revoluto. Inflorescencias de 5.5-8 cm de largo, dispuestas en espigas; brácteas y bractéolas de ca. $1 \mathrm{~mm}$ de largo, cimbiformes, margen eroso. Flores actinomórficas, aromáticas; sépalos 5, de $3 \times 2 \mathrm{~mm}$, elípticos, cara externa glandular rojiza hacia el ápice; pétalos 5, de 9-10 × $3 \mathrm{~mm}$, de color amarillo-crema, oblanceolados, glabros, la base cuneada, el ápice irregularmente emarginado; estambres 10, heteromorfos, 5 largos y 5 cortos, los cortos de $3 \mathrm{~mm}$ de largo, los largos de $4 \mathrm{~mm}$ de largo; gineceo apocárpico, carpelos 2, uno abortivo, de $3 \mathrm{~mm}$ de largo, cada uno con dos óvulos colaterales, generalmente uno abortivo. Fruto pseudodrupa esférica, de $1.5 \mathrm{~cm}$ de diámetro, sésil o con pedicelo de menos de $1 \mathrm{~mm}$ de largo, exocarpio papiráceo de color rojo, mesocarpio delgado, negro, endocarpio lignificado, rojizo. Semilla $1 \times$ $1.2 \mathrm{~mm}$, subesférica; testa esponjosa.

Tipo: MÉXICO. Guerrero, municipio Cocula, Ejido La Fundición, cerro El Limón, ladera norte, bosque tropical caducifolio, $18.000855^{\circ} \mathrm{N}, 99.729310^{\circ} \mathrm{O}, 1131 \mathrm{~m}$, 12 marzo 2013 (flor), A. González-Murillo 667 (holotipo: FCME; isotipo: IEB). Fig. 1.

Distribución y ecología. Por el momento solo se ha localizado en el estado de Guerrero dentro de la cuenca del río Balsas, se distribuye entre los 1000 y $1200 \mathrm{~m}$ s.n.m., en el bosque tropical caducifolio, en pendientes fuertes con suelos someros de origen calizo. Se le encuentra asociada a Bursera aptera Ramírez, Cedrela salvadorensis Standl., Senna wislizeni (A. Gray) H. S. Irwin \& Barneby, Pseudosmodingium perniciosum (Kunth) Engl. y Beaucarnea hiriartae L. Hern. Las flores son visitadas por abejas.

Fenología. Florece y fructifica en marzo cuando ha perdido las hojas o se presentan las primeras hojas jóvenes.

Nombres comunes. Querengoro, sasanaco.

Etimología. El epíteto específico hace alusión al hecho de que las flores son sésiles. 
González-Murillo et al.: Recchia sessiliflora (Surianaceae), una nueva especie de Guerrero, México

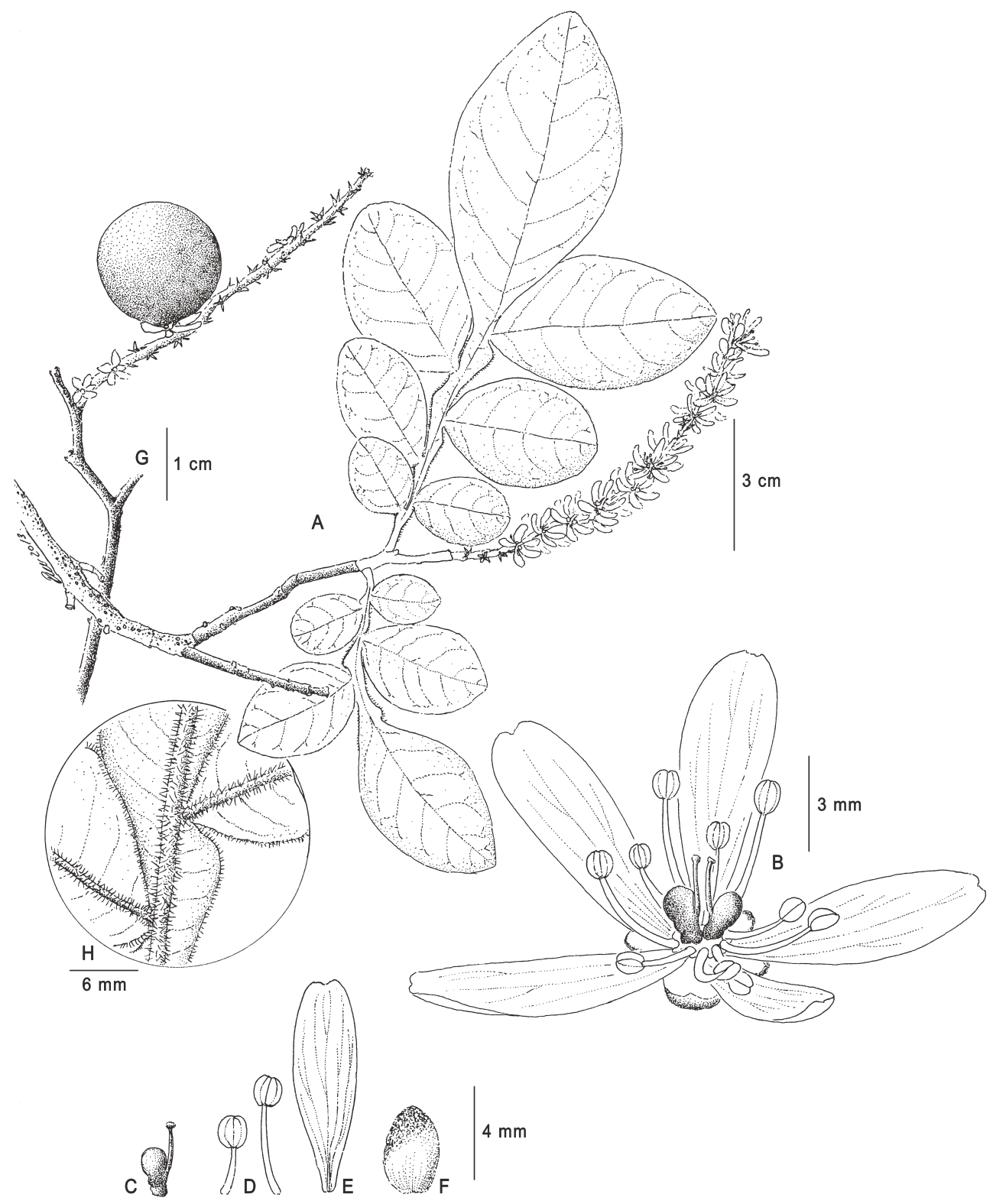

Fig. 1. Recchia sessiliflora González-Murillo \& Cruz Durán. A. rama con hojas e inflorescencia; B. flor completa; C. carpelo; D. estambres; E. pétalo; F. sépalo; G. fruto; H. pubescencia del envés de la hoja. (A-F dibujado de A. González-Murillo 667, FCME; G de C. Sanginés s.n., FCME; H. de A. González-Murillo 550, FCME). Ilustración de Ramiro Cruz Durán. 
Ejemplares adicionales examinados. MÉXICO. Guerrero, municipio Cocula, Ejido La Fundición, cerro El Limón, ladera norte, bosque tropical caducifolio, UTM Q14, 422206X, 1990953Y, 1131 m, 12 marzo 2013 (fruto), C. Sanginés F. s.n. (FCME); Fundición, cerro El Limón, ladera norte, bosque tropical caducifolio, UTM Q14, 422951 X, 1990609 Y, 1042 m, 23 octubre 2013 (estéril), A. González-Murillo 550 (FCME, IEB).

La identidad de Recchia sessiliflora como una especie nueva está respaldada no solo por las características morfológicas distintas a los de otros componentes de Recchia (Cuadro 1), sino por su aislamiento geográfico de ellos. La distribución del género está circunscripta en términos generales a México (Fig. 2) y específicamente al bosque tropical caducifolio, donde se encuentran dos de las tres especies reconocidas. Es posible relacionar a $R$. connaroides y $R$. mexicana, ya que ocupan las áreas bajas cercanas a la costa del Océano Pacífico, generalmente entre los 100 y los 500

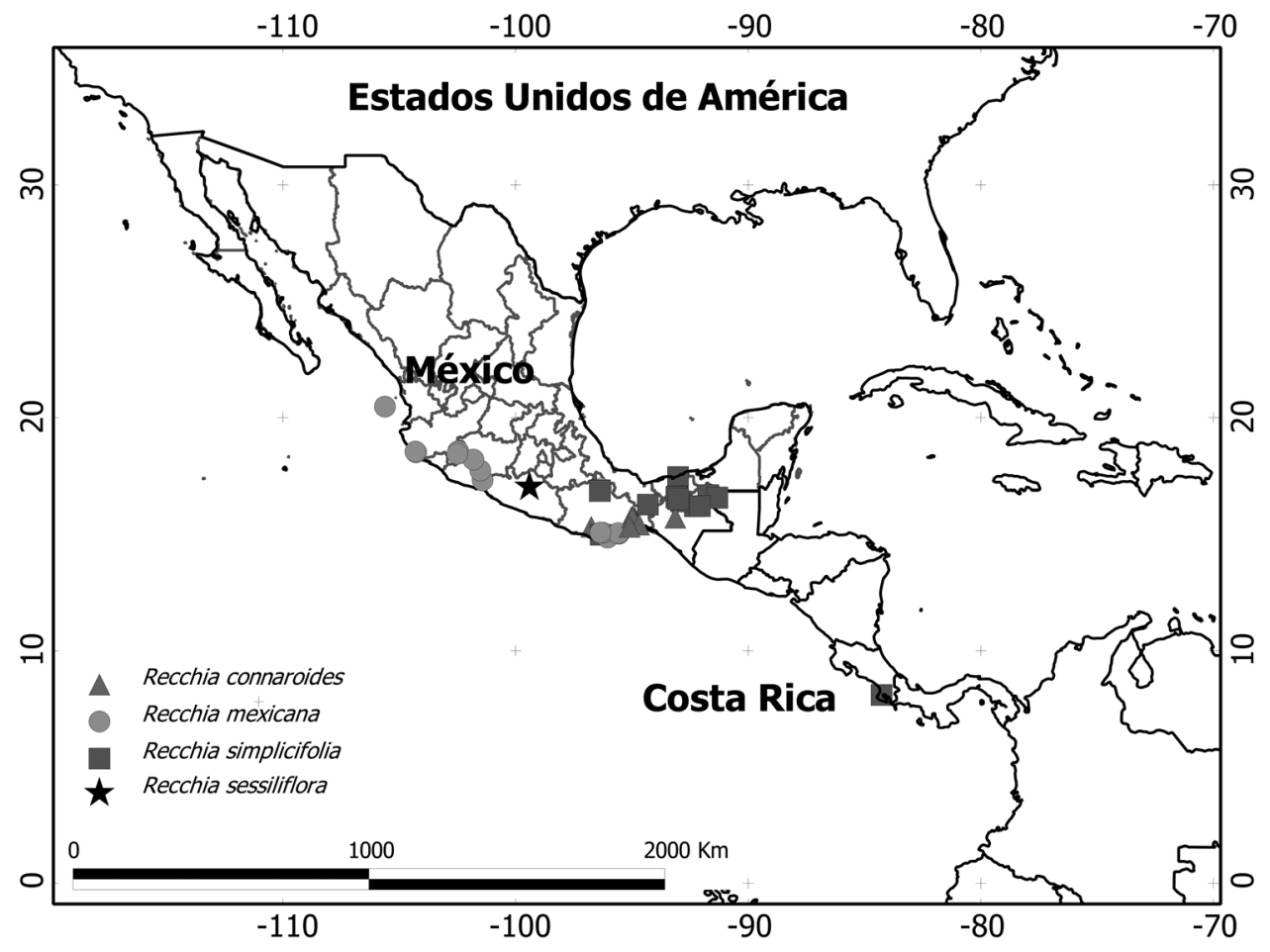

Fig. 2. Distribución conocida del género Recchia. 
Cuadro 1. Comparación entre Recchia connaroides y R. sessiliflora.

\begin{tabular}{|c|c|c|}
\hline & R. connaroides & R. sessiliflora \\
\hline Hojas (tamaño cm) & $9.5-18(-21)$ & $(5.8-) 9.2-12.8(-14.5)$ \\
\hline Pecíolos (tamaño cm) & $1.5-2$ & $(0.5-) 1.1-1.3$ \\
\hline Raquis (alas, tamaño mm) & 3 o menos & hasta 4 \\
\hline Folíolos (forma, tamaño $\mathrm{cm}$ ) & $\begin{array}{l}\text { elíptico-ovados a oblongos, } \\
3.5-9.5(-10.5) \times 1.8-4(-4.5)\end{array}$ & $\begin{array}{l}\text { elípticos, raramente } \\
\text { orbiculares, }(2.3-) 2.7-6.1 \\
(-6.8) \times(1.6-) 2-3.4\end{array}$ \\
\hline Folíolos, pubescencia & $\begin{array}{l}\text { subglabros, solo con } \\
\text { escasos pelos en las venas } \\
\text { principales }\end{array}$ & $\begin{array}{l}\text { haz y envés velutinos, } \\
\text { pubescencia más densa en } \\
\text { las venas de segundo, tercero } \\
\text { y cuarto grado del envés }\end{array}$ \\
\hline $\begin{array}{l}\text { Inflorescencia (forma, } \\
\text { tamaño } \mathrm{cm} \text { ) }\end{array}$ & racemosa, $7-11.5(-15)$ & espiga, $5.5-8$ \\
\hline Flor, pedicelo (tamaño mm) & $1.5-2.5$ & sésil \\
\hline Fruto, pedicelo & acrescente, $2-4.5 \mathrm{~mm}$ & $\begin{array}{l}\text { sésil u ocasionalmente hasta } \\
1 \mathrm{~mm}\end{array}$ \\
\hline Pétalos (forma, tamaño mm) & $\begin{array}{l}\text { ampliamente espatulados, } \\
(6.5-) 9.5-13 \times 2.8-5\end{array}$ & oblanceolados, 9-10x3 \\
\hline Pétalos, ápice & obtuso & irregularmente emarginado \\
\hline Pétalos, base & unguiculada, uña hasta $3 \mathrm{~mm}$ & cuneada \\
\hline Altitud (m) & $30-450(-1450)$ & $1000-1200$ \\
\hline Distribución & $\begin{array}{l}\text { vertiente del Pacífico, } \\
\text { Oaxaca y Chiapas }\end{array}$ & Cuenca del Balsas, Guerrero \\
\hline
\end{tabular}

m s.n.m. (excepcionalmente a los $1450 \mathrm{~m}$ ), mientras que $R$. simplicifolia crece en los bosques tropicales perennifolios. Por otro lado, $R$. sessiliflora se ha encontrado entre los 1000 y los 1200 m s.n.m. en la Cuenca del Balsas, un área ampliamente reconocida por tener un gran número de endemismos (Rodríguez-Jiménez et al., 2005; Rzedowski et al., 2005), principalmente del género Bursera (Burseraceae) y Thompsonella (Crassulaceae).

Clave para las especies conocidas del género Recchia Sessé \& Moc. ex DC.

1 Hojas simples; distribución en bosque tropical perennifolio, en México (Veracruz, norte de Oaxaca y Chiapas, y sur de Tabasco) y Costa Rica R. simplicifolia 
1 Hojas compuestas; distribución en bosque tropical caducifolio, en México (Nayarit a Oaxaca).

2 Alas del raquis de $3 \mathrm{~mm}$ de ancho o menos; inflorescencias compuestas (racemosas); flores pediceladas; frutos con pedicelos acrescentes; vertiente del Pacífico.

3 Folíolos subglabros, solo con escasos pelos en las venas principales; raquis con ala inconspicua de menos de $1 \mathrm{~mm}$ de ancho ................. R. mexicana

3 Folíolos pubescentes, con el haz y envés velutinos, pubescencia más densa en las venas del envés; raquis con ala conspicua de 1-3 mm de ancho ........ $R$. connaroides

2 Alas del raquis de $4 \mathrm{~mm}$ de ancho; inflorescencias en espiga; flores sésiles; frutos sésiles, en ocasiones con pedicelo de menos de $1 \mathrm{~mm}$; cuenca del río Balsas en Guerrero

R. sessiliflora

\section{AGRADECIMIENTOS}

A Martha Martínez por la diagnosis en latín; a José Antonio Hernández, Laboratorio de Microcine, Facultad de Ciencias de la Universidad Nacional Autónoma de México, por la digitalización de la ilustración de la especie; a la Dirección General de Asuntos del Personal Académico de la Universidad Nacional Autónoma de México por la ayuda económica a través del Programa de Apoyo a Proyectos de Investigación e Innovación Tecnológica (PAPIIT IN214112).

\section{LITERATURA CITADA}

Crayn, D. R., E. S. Fernando, P. A. Gadek y C. J. Quinn. 1995. A reassessment of the familial affinity of the Mexican genus Recchia Moc. et Sessé ex DC. Brittonia 47(4): 397-402.

Cronquist, A. 1981. An integrated system of classification of flowering plants. Columbia University Press. Nueva York, USA. pp. 583-585.

Gutiérrez, B. C. 2011. La familia Surianaceae en México. For. Ver. 13(2):1-6.

Kubitzki, K. 2007. Introduction to Fabales. In: Kubitzki, K. (ed.). The families and genera of vascular plants. Vol. 9. Springer-Verlag. Heildelberg, Alemania. p.5.

Rodríguez-Jiménez, C., R. Fernández-Nava, M. L. Arreguín-Sánchez y A. RodríguezJiménez. 2005. Plantas vasculares endémicas de la cuenca del río Balsas, México. Polibotánica 20:73-99.

Rzedowski, J. y G. Calderón. 2013. Datos para la apreciación de la flora fanerogámica del bosque tropical caducifolio de México. Acta Bot. Mex. 102: 1-123. 
Rzedowski, J., R. Medina-Lemos y G. Calderón de Rzedowski. 2005. Inventario del conocimiento taxonómico, así como de la diversidad y del endemismo regionales de las especies mexicanas de Bursera (Burseraceae). Acta Bot. Mex. 70: 85-111.

Schneider, J. V. 2007. Surianaceae. In: Kubitzki, K. (ed.). The families and genera of vascular plants. Vol 9. Springer-Verlag. Heidelberg, Berlin, Alemania. pp. 449-455.

Stevens, P. F. 2001 (y en adelante). Angiosperm Phylogeny Website. Versión 12, julio 2012, http://www.mobot.org/MOBOT/research/APweb/

Thomas, W. W. 1990. The American genera of Simaroubaceae and their distribution. Acta Bot. Bras. 4(1): 11-18.

Thompson, I. A., Ladiges, P. L. y J. H. Ross. 2001. Phylogenetic studies of the tribe Brongniartieae (Fabaceae) using nuclear DNA (ITS-1) and morphological data. Syst. Bot. 26(3): 557-570.

Tropicos.org. 2013. Missouri Botanical Garden. Consultado el 22 julio de 2013, http://www. tropicos.org/Name/29400177

Villaseñor, J. L. 2004. Los géneros de las plantas vasculares de la flora de México. Bol. Soc. Bot. Méx. 75: 105-135.

Wendt, T. y E. J. Lott. 1985. A new simple-leaved species of Recchia (Simaroubaceae) from southeastern México. Brittonia 37(2): 219-225. 